\title{
Laboreal
}

Volume $3 \mathrm{~N}^{\circ} 2$ | 2007

Trabalho infantil

\section{Número especial : Trabajo infantil}

Dossier temático : Trabalho infantil

Dossier thématique : Le travail infantil

Thematic files : Child labour

\section{Maria de Fátima Pereira Alberto y Mary Yale Neves}

\section{OpenEdition}

\section{Journals}

Edición electrónica

URL: http://journals.openedition.org/laboreal/12244

DOI: 10.4000/laboreal.12244

ISSN: 1646-5237

\section{Editor}

Universidade do Porto

\section{Referencia electrónica}

Maria de Fátima Pereira Alberto y Mary Yale Neves, « Número especial : Trabajo infantil », Laboreal [En línea], Volume 3 N$^{\circ} 2$ | 2007, Publicado el 01 diciembre 2007, consultado el 10 diciembre 2020. URL: http://journals.openedition.org/laboreal/12244 ; DOI : https://doi.org/10.4000/laboreal.12244

Este documento fue generado automáticamente el 10 diciembre 2020.

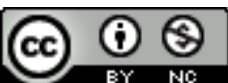

Laboreal está licenciado com uma Licença Creative Commons - Atribuição-NãoComercial 4.0 Internacional. 


\title{
Número especial : Trabajo infantil
}

\author{
Dossier temático : Trabalho infantil \\ Dossier thématique : Le travail infantil \\ Thematic files : Child labour
}

Maria de Fátima Pereira Alberto y Mary Yale Neves

1 La organización de este número especial de la Revista Laboreal sobre el Trabajo Infantil resulta de varios contactos mantenidos con investigadores ligados a Universidades y profesionales liga- dos a instituciones de intervención, atención y defensa de los derechos de los niños y del adolescente en varios países de Europa, África y Latinoamérica.

2 En el mundo de hoy, de todos los niños y adolescentes en la franja de 5 a 17 años, más de 200 millones son trabajadores. Las causas son macro estructurales y micro estructurales, con destaque para la pobreza de los países y para la falta o inefica- cia de las políticas sociales de interés de niños y adolescentes. De entre los países con mayor número de trabajadores infanti- les, se destacan particularmente los de África, Asia y Latinoamé- rica. Ellas trabajan en varias actividades de trabajo en los sec- tores agrícolas, industria, servicio (incluyendo doméstico), comercio y minas. Pero hay, también, trabajo infantil en países de economía desarrollada o industrializados como los Estados Unidos y países de Europa.

3 La actividad que se destaca en cada país se vincula a la estruc- tura económica y a su cultura. Aunque las características que sobresalen estén ligadas a la informalidad de la economía de aquellos países donde los derechos de los niños no son priori- dades, aliados a crisis, catástrofes, guerras y organización del crimen, se destacan, de forma general, aquellas actividades que la OIT cunó en 1999, en la Convención 182, de Peores Formas de Trabajo Infantil. Son ellas : todas las formas de esclavitud, trabajo forzado, tráfico, reclutamiento para conflictos armados, explotación sexual comercial, en fin, trabajos que, por su natu- raleza o por las circunstancias en que son desarrollados, son susceptibles de perjudicar la salud, la seguridad y la moral de los niños.

4 Las consecuencias de la inserción precoz en el trabajo alcanzan integralmente al niño y al adolescente, desde el desarrollo físi- co, psíquico, escolar, social hasta su ciudadanía. 
La inserción precoz es dañina en la vida de esos niños y adolescentes, de entre otros aspectos, porque les niega la infancia, etapa impor- tante en el proceso de desarrollo cognitivo y emocional ; expro-

pia la subjetividad; promueve analfabetismo, baja escolaridad, huida escolar ; causa deformaciones corporales y debilidades físicas que alteran el peso/altura; puede causar accidentes con traumatismos y enfermedades relacionadas con el trabajo; priva de derechos y no posibilita el acceso a la formación para el trabajo en la vida adulta. Las implicaciones psicosociales po- drán aparecer en los siguientes aspectos : una imagen negativa de si y una baja autoestima, la maduración precoz, socialización desviante y la falta de perspectivas de futuro.

6 Para hacer frente a la violencia del trabajo infantil, hay una serie de instrumentos internacionales y nacionales propios a cada país. De entre los instrumentos internacionales, se destaquen los de la Organización de las Naciones Unidas: la Declaración de Ginebra de 1924, la Declaración de los Derechos del Niño de 1959, la Convención sobre los Derechos del Niño de 1989, ade- más de los documentos pertinentes a las agencias Internaciona- les, la Convención 138, la Recomendación 146, la Convención 182 y la Recomendación 190, ambas de la OIT. En el caso de los documentos específicos de la OIT, ellos tratan específicamente sobre la edad mínima, las peores formas de trabajo infantil y recomiendan acciones inmediatas para la erradicación.

7 En 1992, la OIT creó el Programa Internacional para Eliminación del Trabajo Infantil (IPEC), que ha servido como modelo para que varios países elaboren Programas y Proyectos de acción para la prevención y la erradicación del trabajo infantil, que tienen, a un, lado, los niños y los adolescentes como sujetos de cuidados y asistencia especiales; $y$, de otro, la familia como grupo fundamental de la sociedad y ambiente para recibir la asistencia y protección. Al Estado cabe garantizar las condicio- nes para que se cumpla la Protección Integral.

8 La idea principal de dedicar un número de la Revista Laboreal al Trabajo Infantil era intentar reunir un conjunto de artículos que presentasen la situación del niño y del adolescente trabaja- dores en algunas partes del mundo, en varias actividades de trabajo, las consecuencias de la inserción precoz y las formas de intervenciones que han sido puestas en práctica, principalmente a través de las políticas públicas bajo la responsabilidad de los Estados.

9 A pesar de lo que ha sido producido sobre el trabajo infantil en el mundo, tanto en la forma de denuncias (los informes de or- ganizaciones internacionales, de entre las cuales la Organizaci- ón Internacional del Trabajo - OIT), como en el formato académico en las áreas de la sociología, de la historia, del derecho, de la educación, de la economía, psicología etc., hay mucho por construir, considerándose las especificidades regionales (de los países), las diferentes actividades de trabajo en las cuales los niños y adolescentes están insertados, las consecuencias para la salud física y mental, las consecuencias económicas del des- gaste de la infancia y una evaluación continua de las formas de enfrentamiento y de las políticas de intervención puestas en práctica en el sentido del enfrentamiento, de la erradicación y de la prevención.

10 En el plan científico, los planteamientos privilegiados por los autores de los artículos aquí presentados, se encuadran sobre- todo, en ciertas tradiciones de la sociología, de la historia cul- tural, de la economía, del derecho del niño y del adolescente, de las políticas públicas, de la psicología y de la salud del tra- bajo. Los artículos plantean 
datos sobre la situación del trabajo infantil en Europa, sobre aspectos ideológicos y de contextuali- zación del desarrollo, además de un análisis de la actividad real de niños y adolescentes trabajadores en condición de calle en Brasil.

11 El artículo del Paone presenta una contextualización histórica mostrando que las leyes y la instrucción escolar contribuirán para disminuir la incidencia del trabajo infantil en Europa desde la revolución industrial. Pero constata, al mismo tiempo, que, de las últimas décadas del siglo XX hasta la actualidad, denun- cias de varias entidades, sobretodo de asociaciones y sindica- tos de trabajadores, revelan el crecimiento del trabajo infantil en la pos-modernidad con características similares a las del pasado. El trabajo infantil aumentó, principalmente, en Europa del Leste y en Europa Central. El autor traza un panorama en que presenta datos del trabajo infantil en Europa y en los Esta- dos Unidos, según los cuales niños y adolescentes, particular- mente hijos de emigrantes, trabajan en varias actividades, de acuerdo con las características económicas de cada país : activi- dad temporal, trabajos de carretera, actividades comerciales pequeñas o en el trabajo doméstico, en los restaurantes, en las empresas de limpiezas, en la construcción civil. Esto implica abandono, fuga y fracaso escolar, accidentes de trabajo y la difusión creciente de formas misturadas de escuela-trabajo. Pre- senta como causas de ese crecimiento, de entre otras, los efec- tos de las políticas conservadoras de los años 80 , la desregula- ción de las políticas protectoras. Todavía el trabajo juvenil también puede ser una estrategia familiar para proveer una experiencia y una inserción profesional, es decir, el trabajo como un valor.

El artículo de Amazarray, Thomé, Poletto y Koller presenta algu- nas reflexiones sobre el trabajo infantil-juvenil. Aborda tres tó- picos: ideologías que sostienen el trabajo precoz ; subjetividad del niño y del adolescente en situación de trabajo y salud del

trabajador infantil. La perspectiva teórica que sostiene el análi- sis es el Planteamiento Bio-ecológico del Desarrollo Humano el cual considera, necesariamente, sus contextos familiares y so- ciales, así como los procesos proximales que establecen a lo largo del tiempo. La mirada sobre la subjetividad procura com- prender el impacto de esa situación en el desarrollo de los niños y adolescentes. El tópico de la salud del trabajador infan- til, a su vez, sistematiza los riesgos y consecuencias del trabajo precoz. Y finaliza apuntando la producción científica incipiente de la Psicología brasileña sobre la temática.

El artículo de Alberto presenta datos de una pesquisa sobre el trabajo precoz en condición de calle en la ciudad de João Pes- soa, en el Estado de Paraíba, en Brasil. La pesquisa fue hecha en los moldes de un estudio de caso, con niños y adolescentes trabajadores en las actividades de vendedores en los semáforos y vendedoras de pensión, cuidantes y niñas en situación de explotación sexual mercantil. Se comprende que la interrelación de las condiciones de trabajo con la organización del trabajo tiene implicaciones para la salud física y mental. Se utilizan como referencias autores que tratan del campo de la salud men- tal, trabajo y subjetividad, particularmente la Psicosociología, la Teoría del Desgaste, la Ergonomía y la Psicodinámica del Traba- jo. Los resultados mostraron que la inserción precoz es nefasta en la vida de esos niños y adolescentes, con implicaciones psi- cosociales que aparecerán en los siguientes aspectos : imagen negativa de si y baja autoestima ; maduración precoz; deficien- cia escolar ; socialización desviante y falta de perspectivas de futuro. 


\section{AUTORES}

\section{MARIA DE FÁTIMA PEREIRA ALBERTO}

Universidade Federal da Paraíba, R. Sebastião Interaminense, no 369 Edifício Porto Lugano, Apartado 202, CEP 58.036-300 Bessa João Pessoa Paraíba - Brasil

falberto@uol.com.br

\section{MARY YALE NEVES}

Universidade Federal da Paraíba, R. Sebastião Interaminense, n 369 Edifício Porto Lugano, Apartado 202, CEP 58.036-300 Bessa João Pessoa Paraíba - Brasil

falberto@uol.com.br 